\title{
New Zealand's Collective Employment Contracts: Update November 1992
}

\author{
Raymond Harbridge*
}

\section{Introduction}

The Employment Contracts Act 1991 contains a very different thrust than that of New Zealand's earlier industrial relations legislation. That thrust is directed at the decollectivisation of the labour relations system, encouraging enterprise bargaining over multiemployer bargaining, and promoting individual rights as equal to those of any collective. A direct corollary of these policies is reflected in the decision to keep no public record of collective bargains. Confidentiality of settlement outcomes has become an important aspect of negotiations. While Government policy has determined that there will be no public record of collective bargains, it has decided that, for "analytical and research" purposes, employers who enter into collective employment contracts that cover 20 or more staff should forward copies of those contracts to the Secretary of Labour. No such obligation rests with unions or other employee organisations who enter into contracts. The absence of a comprehensive public record of collective bargaining has made it very difficult to ascertain the effects of the legislation, but then, that is something that can be used to advantage by those who support the Act.

The Minister of Labour, the Hon. W. F. Birch, told a London audience in mid October that "union scaremongering" had fuelled employees fears that wages would fall following the passing of the Employment Contracts Act ${ }^{1}$. Birch reported that this union scaremongering had since been discredited and that in fact wage levels had increased by approximately three percent since the introduction of the Act. Birch based his "three percent" claim on the May 1992 Quarterly Employment Survey (QES) which reported a three percent increase in the total weekly earnings. Traditionally in New Zealand, Ministers of Labour have played a significant role in lowering expectations and talking the wage round "down". Birch, however, has had an each way bet, talking down expectations in the public sector, but talking the wage round "up" to three percent at various opportunities.

Industrial Relations Centre, Victoria University of Wellington. Nick Howard, James Moulder and Charlie Welch provided invaluable research assistance. The research has been supported by research grant RGNT 184 from the University's Internal Grants Committee and a further grant from the Faculty of Commerce and Administration.

1 Rt Hon Bill Birch, Address to the Confederation of British Industry, London, 20 October, 1992, p.11 
My view is that the three percent figure must have been a shock to many employers and workers - who had neither paid (nor been paid) such an increase. Political satirist and cartoonist Tom Scott no doubt reflected the views of many when he portrayed the Minister as a teller of "fairytales" with his "three percent" claim². The difficulty with the "three percent" is that it just doesn't match the reality of people's experiences. And that's part of the difficulty with monitoring the new legislation and its effects. The total picture has been the difficulty with monitoring the new legislation and its effects. The total picture has been with people's reality.

Given this new Government policy, primary data gathering has become a necessary first step for any comprehensive review of the effects of the employment contracts legislation. For the for any comprehensive review of the effects of the employment contracts legislation. For the research reported here, primary data gathering has consisted of attempting to collect as many
collective employment contracts as is possible, irrespective of the size of each contract. A multi-faceted approach to this data gathering has been adopted and a number of successful surveys are being undertaken. In a small country such as New Zealand (a country that really must be seen as a slightly overgrown fishing village), it is not that difficult to find out what's presented here speak for themselves in terms of response rates and overall coverage.

The first survey has been of employers of 50 or more staff as listed in the New Zealand Business Who's Who. There are 1,200 employers (with a total of 430,000 staff) listed as having 50 or more staff. In the period August - October 1991, these employers were asked whether they would be prepared to forward copies of their collective employment contracts s part of this research project. As at November 1992, 800 employers $(280,000$ staff $)$ had replied - 67 percent of those surveyed.

Of the 800 respondents, 184 employers (96,000 staff) had already forwarded collective employment contracts and a further 235 employers $(50,000$ staff) offered to forward contracts when they were settled. One hundred and sixty three employers $(59,000$ staff) indicated that they did not want to take part in the survey (confidentiality being the most quoted reason for not wanting to take part), and 175 employers (with just 48,000 staff) indicated that they would be negotiating individual contracts only. A settlement registered under the Labour Relations Act 1987, which has been taken as an indication that support for the project is forthcoming, was forwarded by 25 employers $(25,000$ staff).

The second survey of employers has been undertaken of employers of 20 - 50 staff, as listed in the New Zealand Business Who's Who. There are 1,429 employers (with a total of 43,000 staff) listed as having between 20 and 50 staff. These employers were written to in June and July 1992 and asked to take part in the study. As at November 1992, 35 percent of those surveyed had replied.

The third survey has been of unions. At 15 May 1991, there were some 80 unions registered under the Labour Relations Act. All of these have been asked if they will supply collective employment contracts as part of the monitoring project. The response has been encouraging with only three unions refusing to supply the collective employment contracts they have negotiated. Union resources have been heavily taxed during this period and forwarding

2 Evening Post, 20 November, 1992, p.4. contracts was unlikely to have been a high priority. Accordingly, regular contact with officials has been an important aspect in maximising coverage with unions.

Other surveys include public sector bargaining (of which there had been little finalised as at August 1992), and the State Services Commission has agreed formally to supply copies of contracts it is associated with; of bargaining agents, some of whom have agreed to endorse the project to their clients; the monitoring of news reports for evidence of the negotiations of and disputes over, collective employment contracts; finally, personal contacts in the labour relations "industry" are ensuring good source collection.

This paper updates a paper prepared for the first anniversary of the Employment Contracts Act on 15 May 1991 (Harbridge and Moulder, 1993). The earlier paper reported collective bargaining trends on the basis of 470 collective employment contracts covering 128,000 employees. The database of collective employment contracts has grown significantly since then. This paper is based on 1,053 collective employment contracts covering 192,000 workers and slightly over 4,000 employers. This sample represents 31 percent of the unionised workforce as at 15 May 1991, 27 percent of workers covered by collective settlements in the 1989/90 wage round, and 17 percent of the full-time workforce.

Unions supplied approximately 60 percent of the contracts and employers 40 percent.

Major contracts settled in the health, education and public service have not been received as yet and are not included in the database. A large number of contracts reported herein and classified as "community, public services" are in the local government sector. Accordingly the trends presented largely reflect private sector movements. The distribution and coverage of contracts by major industry classification is presented in Table 1.

Table 1: The distribution and coverage of contacts by industry

\begin{tabular}{lccc} 
Industry & No of contracts & Coverage & $\%$ Coverage \\
\hline Manufacturing & 478 & 42,292 & $22 \%$ \\
Wholesale, retail, hotel, etc & 104 & 35,733 & $18 \%$ \\
Transport, communication & 77 & 27,970 & $15 \%$ \\
Finance & 86 & 36,359 & $19 \%$ \\
Community, public services & 188 & 36,115 & $19 \%$ \\
Other & 120 & 14,146 & $7 \%$ \\
\hline Totals & 1,053 & 192,615 & $100 \%$ \\
\hline
\end{tabular}

We have identified 173 contracts covering 124,000 employees ( 65 percent) that are national contracts applying in enterprises that have operations throughout the whole of New Zealand.

The research methodology adopted has returned a dataset of larger employers; however, many of the union supplied contracts cover smaller work-places. The concentration of workers 


\section{Raymond Harbridge}

covered by the contracts is presented in Table 2 . The data shows the dominance of the large employer sector with 68 percent of coverage being in just 67 contracts settled with employers who have 500 or more staff. While the paper reports on over 600 contracts where the employer has less than 50 staff, these contracts cover just seven percent of all workers in the survey. Clearly, a very strong bias in this sample of contracts is towards the very large employer sector, and particularly employers who have operations throughout New Zealand. However, notwithstanding this, a large number of contracts covering smaller employers have been included and analysed.

Table 2: The number of employees covered by each contract

Number of employees

Contracts

Coverage $\%$ coverage

Under 20 employees

20 - 49 employees

50 - 99 employees

100 - 499 employees

500 - 999 employees

Over 1000 employees

Total

\begin{tabular}{rrr}
282 & 2,838 & $2 \%$ \\
331 & 9,656 & $5 \%$ \\
181 & 11,607 & $6 \%$ \\
192 & 37,397 & $19 \%$ \\
33 & 21,115 & $11 \%$ \\
34 & 110,002 & $57 \%$ \\
\hline & & \\
1,053 & 192,615 & $100 \%$ \\
\hline
\end{tabular}

While the Employment Contracts Act took effect on 15 May 1991, various transitional arrangements ensured a staggered implementation of these new bargaining arrangements. Settlements registered under the Arbitration Commission were valid until their stated expiry date. As at November 1992, there were just 57 such settlements covering some 18,000 workers that remained current. The "old" system is very very dead now - just 18 months out from the enactment of the employment contracts legislation.

The data presented in Table 3 allows a comparison of collective bargaining under the Labour Relations Act system and that which has been identified under the Employment Contracts Act. The figure reported for 1989/90 can be assumed, for all intents and purposes, to represent all bargaining under the old system. Data for the coverage of collective employment contracts that have been obtained for this study are also presented. Clearly, however, this is an incomplete set of data. It is reasonably expected that the major contracts negotiated have been sighted and incorporated in this dataset. In Table 3, allowance is made for 30,000 workers covered by collective bargains not held, and a further 150,000 education, health and public sector workers whose awards and collective agreements expired around 30 June 1992 Some of these have settled, and more are expected to settle over the next few months.
Table 3: Collective bargaining coverage 1989/90 - 1991/92: an estimate of the collapse of collective bargaining as at November 1992

Legislative period

Collective Bargaining Coverage

Labour Relations Act settlements 1989/90

Unexpired Labour Relations Act settlements 1991/92

Collective employment contracts obtained 1991/92

Expected public sector settlements to come 1991/92

Allowance for contracts not obtained

Minimum coverage 1991/92 current settlements

18,000

192,000

150,000

30,000

$390 ; 000$

Difference in coverage $1989 / 90$ to $1991 / 92$

331,000

The estimated collapse of collective bargaining coverage is some 331,000 workers - a drop of 45 percent in just two years - a very major collapse of New Zealand's collective bargaining system. There is no way of identifying at this point what bargaining, if any, has taken place for this group of workers, or whether in fact these workers have any written employment contract at all. Technically these workers have moved to individual contracts in the absence of a collective contract. The unknown variable in this move is whether the move was an "up" movement or a "down" movement. It seems likely, for example, that middle management removed from a collective settlement and placed on an individual contract may well have received additional benefits as part of that move. On the other hand, media reports over the last year or so have identified many individual workers who have received pay cuts as a result of being required to move to individual contracts. On balance it seems almost certain that there has been more "down" movement than "up" movement for individuals who have been placed on individual employment contracts.

\section{The structure of collective employment contracts}

Notwithstanding this collapse of collective bargaining, an important level of collective bargaining has taken place under the employments contracts legislation. While union influence has been trimmed, it hasn't been completely broken. Around 350,000 workers remain unionised (down from 610,000 members in March 1991) and covered by union negotiated collective settlements. There can be no doubt that union membership has declined, but unions have retained an important influence in bargaining. Approximately 80 percent of workers in this survey are covered by a union negotiated contract.

Enterprise bargaining has become very much the norm and multi-employer contracts cove just 15 percent of the workers in the sample. Most of these enterprise bargains are genuine enterprise bargains, covering all unionised employees engaged by that employer. Of the 4,000 employers in this dataset, there were just 49 who had entered into more than one collective employment contract for their staff, and often these different contracts were settled on a site

by site rather than an occupational basis. 
A number of employers have forwarded, for inclusion in the database, individual contracts that are the same for all their workers. These have been treated as collective contracts and included in the dataset. The types of employment contracts are presented in Table 4.

\section{Table 4: The type of employment contracts}

\begin{tabular}{lrrr} 
Contract type & Contracts & Coverage & $\%$ coverage \\
\hline Multi-employer/multi-union cecs & 6 & 11,752 & $6 \%$ \\
Multi-employer/single union cecs & 14 & 12,190 & $6 \%$ \\
Multi-employer/no union cecs & 4 & 5,210 & $3 \%$ \\
Single employer/multi-union cecs & 150 & 38,230 & $20 \%$ \\
Single employer cecs & 791 & 114,868 & $60 \%$ \\
Individual employment contracts & 88 & 10,387 & $5 \%$ \\
\hline Total & 1053 & 192,637 & $100 \%$ \\
\hline
\end{tabular}

Unions have been involved in contract settlements covering 80 percent of the employees in the sample, and are party to over 200 contracts, being nearly 25 percent of the contracts in the sample. Company based worker bargaining agents have settled 23 contracts covering 9,000 workers, and there appears to be no representation at all for employees in nearly 300 contracts covering 30,000 workers. Multi-employer bargaining has, as anticipated, all but disappeared. Just 24 settlements covering 29,000 workers were multi-employer. The predominant bargaining type is enterprise based.

Many unions have attempted to become party themselves to contracts they have entered into. The main reasons for this are to simplify the process of contract enforcement and to enable new union members to link more easily to existing contracts. Unions are party to 220 contracts covering 47,000 workers. In the balance of cases, workers alone are party to the settlements.

Five unions (Northern Distribution Workers, Engineers, FinSec, Service Workers, and the Communication and Energy Workers) were key players in bargaining - together accounting for 42 percent of all contracts and covering 54 percent of all workers in the survey.

\section{The content of contracts: wages}

Determining how wages have moved under the Employment Contracts Act presents all kinds of difficulties. First, there is a very large number of workers who appear to have no collective employment contracts in place and about whom we can make no estimates of wage change. Second, 208 contracts in our sample, covering 22,000 individuals, don't contain any wage rates. Presumably the workers covered by the contract also have individual contracts containing their wage rate, in addition to the terms contained in the collective contract. Third, there have been obvious restructurings of the terms of employment, and "trade-offs" between certain conditions (primarily penal rates) and wage increases. Where we have observed these restructured contracts, we have not calculated the wage increase and have classified the settlement as "other". Fourth, it is important to compare "apples with apples", and thus, the wage increase needs to be considered both as a raw and an annualised increase. The annualised movement expresses the value of the raw wage movement over a 12 month period, and takes into account factors such as whether the increase is backdated to the expiry of the predecessor contract, whether the increase is stepped, etc (Ansell, Brosnan and Harbridge, 1990). In many cases, while we can identify the raw increase, we have been unable to annualise the increase as the contract contains no specific expiry date. There are 65 contracts that do not contain any expiry date. A further 85 contain a clause that indicates how the contract can be terminated rather than specifying a date of termination. Fifth, we have had considerable difficulty identifying the contract's parentage under the old system. In some cases, there are genuinely new contracts where no comparison with old rates is possible.

Notwithstanding these difficulties, we have tracked the wage increase of 119,000 workers in the sample. The data presented represents genuine wage changes rather than artificia increases that really only reflect the changed structure of the contract. We present two tables of data showing the level of wage movement.

In Table 5, the wage increase in each contract has been weighted by the number of workers covered by that contract so as to produce a weighted mean wage increase. The data are presented by selected industries and for all sectors. Further the data are presented by raw and annualised increase.

Table 5: Weighted mean wage increments by selected industries

\begin{tabular}{lccccc} 
& \multicolumn{2}{c}{ Mean raw wage change } & & \multicolumn{2}{c}{ Mean annualised wage change } \\
\cline { 5 - 6 } Industry & Change & Coverage & & Change & Coverage \\
\hline Manufacturing & $0.6 \%$ & 17,893 & $0.3 \%$ & 17,653 \\
Wholesale, retail, hotel etc & $0.3 \%$ & 24,294 & $0.0 \%$ & 22,229 \\
Transport, communication & $0.1 \%$ & 20,748 & $0.0 \%$ & 20,748 \\
Finance & $0.2 \%$ & 32,731 & $0.2 \%$ & 32,731 \\
Community, public services & $0.3 \%$ & 18,196 & $0.1 \%$ & 13,020 \\
\hline All sectors & $0.3 \%$ & 119,507 & $0.1 \%$ & 111,969 \\
\hline
\end{tabular}

The data show a raw wage movement of 0.3 percent across all sectors, but this increase drops to just 0.1 percent when annualised. There are some differences according to sector. The manufacturing sector contracts show the largest weighted average increase for raw wage increases but this flattens out considerably when annualised. The finance sector has attracted a 0.2 percent increase that annualises at 0.2 percent, on the basis that nearly all settlements were for a 12 month term. 
Large employers have been the least likely to give any wage increase. Employers of 500 or more staff negotiated a raw mean wage increase of 0.3 percent (an annualised increase of 0.1 percent). In fact most of these large employers gave a zero wage increase. Smaller employers in all size groups (under 20 employees, 21 - 50 employees, 51 - 100 employees, 101 - 200 employees, 201 - 500 employees) settled for identical raw mean wage increases of 0.6 percent (an annualised increase of 0.4 percent).

For all intents and purposes, there has been no wage movement under the Employment Contracts Act, as the level of movement reported is minuscule.

Notwithstanding the fact that the overall level of settlement is all but completely flat, some workers have experienced significant wage increases over the last 18 months. Around 38,000 workers have received raw wage increases of four percent or more - over 10,000 of these attracting raw increases in excess of 10 percent. Two distinct patterns of wage settlement have occurred - roll-over settlements with a zero wage increase and settlements that annualise at over one but less than two percent. The dispersion of wage settlements is presented in Table 6.

Table 6: Wage increases in collective employment contracts

\begin{tabular}{|c|c|c|c|c|c|c|}
\hline & \multicolumn{3}{|c|}{ Raw wage increments } & \multicolumn{3}{|c|}{ Annualised wage increments } \\
\hline & Contracts & Coverage & \%Cover & Contracts & Coverage & \% Cover \\
\hline Wage decrease & 10 & 8,371 & $7 \%$ & 10 & 8,371 & $7 \%$ \\
\hline Zero wage increase & 145 & 47,021 & $39 \%$ & 148 & 47,501 & $42 \%$ \\
\hline Under $1 \%$ increase & 10 & 470 & $0 \%$ & 49 & 3,876 & $3 \%$ \\
\hline $1-1.9 \%$ increase & 52 & 16,637 & $14 \%$ & 66 & 28,822 & $26 \%$ \\
\hline $2-2.9 \%$ increase & 72 & 5,794 & $5 \%$ & 75 & 7,838 & $7 \%$ \\
\hline $3-3.9 \%$ increase & 46 & 3,312 & $3 \%$ & 31 & 2,962 & $3 \%$ \\
\hline $4-4.9 \%$ increase & 34 & 8,722 & $7 \%$ & 22 & 4,013 & $4 \%$ \\
\hline $5-5.9 \%$ increase & 19 & 4,072 & $3 \%$ & 12 & 652 & $1 \%$ \\
\hline $6-6.9 \%$ increase & 11 & 1,176 & $1 \%$ & 12 & 1,327 & $1 \%$ \\
\hline $7-7.9 \%$ increase & 9 & 7,714 & $7 \%$ & 6 & 258 & $0 \%$ \\
\hline $8-8.9 \%$ increase & 6 & 1,320 & $1 \%$ & 13 & 2,084 & $2 \%$ \\
\hline $9-9.9 \%$ increase & 7 & 4,660 & $4 \%$ & 6 & 737 & $1 \%$ \\
\hline $10-20 \%$ increase & 60 & 7,384 & $6 \%$ & 44 & 2,349 & $2 \%$ \\
\hline Over $20 \%$ & 42 & 2,854 & $2 \%$ & 15 & 1,179 & $1 \%$ \\
\hline Totals & 523 & 119,507 & $99 \%$ & 509 & 111,969 & $100 \%$ \\
\hline Other & 322 & 51,255 & 336 & 58,793 & & \\
\hline Individual pay rates & 208 & 21,875 & 208 & 21,875 & & \\
\hline
\end{tabular}

A minimum adult wage is contained in 857 contracts and the mean weekly wage is $\$ 341$ per week. Fifty percent of contracts now provide for a minimum adult wage of $\$ 328$ per week or less, and 12 contracts provide for a rate lower than the statutory minimum adult wage of $\$ 245$ per week. 370 contracts covering 98,000 workers provide for a minimum adult wage rate of $\$ 8.00$ per hour or less.

Overall there appears to be some pressure on the minimum wage in each contract and these rates have dropped on average by about $\$ 3.00$ per week in the contracts we are seeing.

There is of course no statutory minimum wage for youth workers. Youth rates are absent in 385 contracts covering 46,000 workers.

Specific productivity linked payments were identified in 44 contracts covering 30,000 workers. Ranges of rates in pay scales remain rare with just 34 contracts covering 17,000 workers containing ranges of rates. As previously reported, ranges of rates are found in the insurance, local government and public sector.

\section{The content of contracts: working time arrangements}

Much of the emphasis in collective bargaining has been on the removal or reduction of penal and overtime rates of pay and associated working time arrangements. A detailed analysis of 770 contracts covering 166,000 employees has been reported elsewhere (Harbridge and Tolich, 1993). The main findings reported are summarised here.

There have been dramatic changes to working time arrangements but these major changes are contained in certain sectors of the economy - in most sectors where collective bargaining has taken place, change has been restricted to removing what one employer described as "the more excessive payments" associated with penal rates. Clock hours of the traditional type that is the normal hours of work paid at ordinary rates of pay which fall between fixed hours (for example 8am to 6pm) on specified days of the week (for example Monday - Friday) are still very prevalent, being present in nearly three quarters of all contracts, covering over 70 percent of employees. Employees are still required to work the same number of hours per week as previously - those on a 37 and a half hour week have retained that, as have those on a standard 40 hour week. A small number of contracts, less than 50 covering under 6,000 workers now provide for ordinary hours in excess of 40 (in most cases a 50 hour week) to be worked at ordinary time rates.

There are important changes in the days of the week in which the ordinary hours can be worked. A growing number of contracts specify that five days can be worked either Monday to Saturday or Monday to Sunday, and an important number of contracts, covering some 26,000 workers, have introduced a four day week Monday - Sunday. The "wholesale, retail, hotel" sector is the most likely to have introduced this four day week which is rare in other sectors, particularly manufacturing. The introduction of the four day week appears to have resulted from a trade off over wages, with contracts introducing the four day week being more likely to settle for wage increases in excess of five percent than contracts that maintained the five day week. 


\section{Raymond Harbridge}

Important changes have been introduced in the application of penal and overtime rates of pay, with a number of clear trends developing. Penal and overtime rates for work outside fixed clock hours still exist in most new contracts; however, the rate for overtime work has changed markedly. Triple time rates have all but disappeared while new, lower penal rates, such as time and a quarter or time plus ten percent, have appeared in some contracts. Double time rates are far less freely available than previously; however, work on Sundays and at nights (10pm to 6am) still attracts double time rates. Time and half is the most common overtime premium now - contracts that had previously contained time and half for the first three hours, then double time, now provide for time and a half throughout. Finally, many previous settlements provided for minimum engagement periods for overtime rates, particularly for Saturday and Sunday work. Generally speaking, the new contracts do not contain that type of provision, and overtime is now paid for the hours actually worked rather than minimum periods of engagement.

\section{Discussion}

The research reported herein indicates that a very major structural change to collective bargaining has taken place. Multi-employer settlements, the mainstay of the bargaining system for the previous 90 years, have been replaced with either single enterprise contracts, or nothing. Overall there appears to have been a collapse of the collective bargaining system with the drop in collective bargaining coverage being estimated at around 45 percent. There is, at this stage, little way of assessing what has happened with this group of 330,000 workers who have fallen out of the collective bargaining system. However, the smart money suggests that these workers have not moved to new individual employment contracts. This speculation is supported by the results of a survey conducted by the Heylen Research Centre and Teesdale Meuli and Co on behalf of the Labour Department which has identified that "approximately 51 percent of employees reported no new employment contract", and further that "out of 1000 employees surveyed only 32 percent were hourly wage earners who had negotiated new employment contracts since May 1991" (Department of Labour, 1992: p.1). The groups of workers previously covered by the award based collective bargaining system were largely hourly wage earners, and it is exactly this group that the Heylen et al research has identified as not receiving replacement contracts. The other important finding regarding the structure of collective bargaining is that the new enterprise contracts are more genuinely enterprise settlements covering all unionised employees engaged by that employer. In practical terms it seems likely that in most cases this has assisted the extension of multi-skilling and removed many, if not all, of the occupational demarcations that existed under the previous system. This alone is undoubtedly improving productivity in many enterprises.

Regarding the content of those collective contracts examined, the data presented herein supports the view that the three percent figure doesn't represent the experience of very many employees, and that on average wages have not moved at all over the last year. So who's right? Have wages flattened out at zero, or is Birch's three percent correct? There are some good technical reasons to doubt the relevance of the QES figure quoted by Birch and these are worth examination.
First, as the Department of Statistics itself points out, "the movements in average earning statistics are not equivalent to those in average pay rate statistics, as earnings statistics are influenced by changes in the composition of the labour force from survey to survey". Now the composition of the workforce is changing. Many low paid workers, particularly in retail have left the workforce. So, the remaining workforce participants are on average higher paid - a source of upward bias in the wage rate calculation in the QES. An example makes it easier to understand. Lets assume that in 1991 there were just 10 wage earners in New Zealand, and that one of them was a doctor earning $\$ 100,000$, with the remaining nine being nurses on wages of $\$ 25,000$. The average wage of the population in 1991 was $\$ 32,500$. Come the beginning of 1992, two of the nurses were made redundant, while the remaining seven nurses and the doctor earned exactly what they earned the previous year. The average wage of the population in 1992 was now $\$ 34,375$, an increase of six percent over the previous year, yet it is clear to all and sundry that the calculated increase in the average wage does not represent a wage increase of six percent at all. The QES figure quoted by the Minister is measuring something quite different.

Second, there is a difficulty with the wage rate measured - the numerator in the equation The QES measures bonuses, commissions and penal rates on top of hourly rates but excludes non-taxable allowances. Many of these allowances have now been incorporated into the base hourly rates, yet the QES data will not identify that. In other words, the numerator is sometimes artificially high as allowances incorporated into the base rate have been treated as wage increases - a second source of upward bias.

Third, there is a problem with the use of "average" in this context. Employees on large salaries who received a wage increase will unfairly affect the mean increase reported by QES for all employees.

There is another official statistic that is useful here. The prevailing weekly wage rates index (PWWRI) - another official measure of wage rate change - paints a very different picture from the QES. It shows only a $0.6 \%$ annual increase in wages to June 1992. This figure also overstates wage increases in the current environment, because only ordinary time pay for fulltime employees is included. As the survey of contracts reported herein shows, ordinary time rates are sometimes being boosted as partial compensation for reduced penal rates and allowances. This erosion of income is not captured by the PWWRI statistic.

Claus Moser, a statistician who's had a law named after him, probably has it right. Moser's law goes something like this -

If you ever find a really interesting statistic, its probably wrong.

In the coming months as we all battle with the flood of information regarding the success or otherwise of the employment contracts legislation, remember Moser. 


\section{Raymond Harbridge}

\section{References}

Ansell J., Brosnan P., and Harbridge R. (1990), When is 3 plus 1 equal to 3.1 ? - methods of examining wage settlements to determine their annual rate of adjustment, New Zealand Journal of Industrial Relations, 15(1): 49-60.

Department of Labour (1992), Contract, Special Edition November, Wellington, Department of Labour.

Harbridge R. and Moulder J. (1993), Collective Bargaining and the Employment Contracts Act: One Year On, The Journal of Industrial Relations, (Forthcoming).

Harbridge R. and Tolich D. (1993), Collective employment contracts and new working time arrangements in New Zealand, Journal of Employment Studies, (Forthcoming).

New Zealand Business Who's Who: 32nd Edition (1991), Wellington, New Zealand Financial Press Ltd. 